\title{
Psicologia e Afetividade em Espinosa: uma revisão crítica sobre o uso da teoria dos afetos
}

\section{Psicología y Afectividad en Espinosa: Una revisión crítica sobre el uso de la teoría del Afecto}

\section{Psychology and Affectivity in Spinoza: a critical review about the use of the theory of affects}

\author{
André Gustavo Imianowsky ${ }^{\mathrm{a}}$ [을 , Carla de Almeida Vitória ${ }^{\mathrm{b}}$ \\ ${ }^{a}$ Fundação Universidade Regional de Blumenau, SC, Brasil \\ Professor da Universidade Regional de Blumenau - Departamento de Psicologia; Mestre em Psicologia Social pela Pontifícia Univer- \\ sidade Católica de São Paulo - PUC/SP. Email: agiwsky@gmail.com. \\ ${ }^{\mathrm{b}}$ Psicóloga pela Universidade Regional de Blumenau - FURB. Email: psicarlavitoria@gmail.com.
}

\begin{abstract}
Resumo: Este trabalho consiste numa investigação que visa analisar as relações existentes na Psicologia acerca da Afetividade a partir das contribuições de Espinosa. Partindo inicialmente de uma revisão bibliográfica em base de dados para conhecer qual a compreensão da Psicologia sobre os afetos, elencou-se três categorias de análise: a) distinção entre usos casuais e sistemáticos da obra de Espinosa; b) conceitos espinosanos que recebem maior atenção ou citação; c) áreas que buscam no autor uma contribuição às suas reflexões. Do total de artigos, 43,75\% fizeram uso casual da referência pessoal ou teoria de Espinosa e 56,25\% fizeram uso sistemático e destacaram a teoria por meio de elaboração reflexiva. Entre os artigos existe a prevalência dos conceitos afeto/afetividade/dimensão afetiva, conatus, encontro, paixão, afecções e imaginação. As áreas que buscam a contribuição do filósofo se destacam em: sócio-histórica; histórico-cultural; educacional; desenvolvimento; clínica; representações sociais; psicanálise na infância.
\end{abstract}

Palavras-chave: Psicologia; Espinosa; Teoria dos Afetos.

Resumen: Este trabajo consiste en una investigación que tiene como objetivo analizar las relaciones existentes en psicología sobre el afecto a partir de las contribuciones de Espinosa. A partir de una revisión bibliográfica en la base de datos para comprender la comprensión de la psicología de los afectos, se enumeraron tres categorías de análisis: a) distinción entre usos casuales y sistemáticos del trabajo de Espinosa; b) conceptos espinosanos que reciben más atención o cita; c) áreas que buscan en el autor una contribución a sus reflexiones. Del total de

Como citar o artigo: IMIANOWSKY, A. G.; VITÓRIA, C. A. Psicologia e Afetividade em Espinosa: uma revisão crítica sobre o uso da teoria dos afetos. Revista de Ciências Humanas, Florianópolis, v. 54, 2020 DOI: 10.5007/2178-4582.2021.e67929 você pode compartilhar, adaptar, para qualquer fim, desde que atribua a autoria da obra, forneça um link para a licença, e indicar se foram feitas alterações. 
artículos, el $43.75 \%$ hizo uso casual de la referencia o teoría personal de Espinosa y el 56.25\% hizo uso sistemático y destacó la teoría a través de la elaboración reflexiva. Entre los artículos se encuentra el predominio de los conceptos de afecto / afectividad / dimensión afectiva, conatus, encuentro, pasión, afectos e imaginación. Las áreas que buscan la contribución del filósofo se destacan en: sociohistórica; histórico-cultural; educativo; desarrollo; clínica; representaciones sociales; psicoanálisis infantil.

Palabras clave: psicología; Espinosa; Teoría del afecto.

\begin{abstract}
This paper consists of an investigation that aims to analyze the existing relations in Psychology regarding Affectivity from Espinosa's contribution. Initially starting from a bibliographic review in database to know about the understanding of Psychology on the affects, three analyzing categories were listed: a) distinction between casual and systematic uses of Espinosa's work; b) Espinosa's concepts that have greater attention or quotation; c) areas that find on the author a contribution to their reflections. From the totality of articles, 43,75\% have made casual use of the personal reference or Espinosa's theory, while 56,25\% have made systematic use and highlighted the theory through a reflexive elaboration. Among the articles there is a prevalence of the concepts of affect/affectivity/affective dimension, conatus, encounter, passion, affections and imagination. The areas that look for the philosopher's contribution stand-out in: social-historical; cultural-historical; educational; development; clinics, social representations; psychoanalysis in childhood.
\end{abstract}

Keywords: Psychology; Espinosa; Theory of Affects.

\title{
1 INTRODUÇÃO
}

A afetividade é um tema que se apresenta sob diferentes perspectivas dentro da Psicologia, ora com marcas fisiológicas, ora subjetivas ou somente como traços relacionais de carinho e atenção. Os diversos usos vêm aparecendo em diferentes momentos desta ciência, expondo o que é o afeto e qual a afetividade da Psicologia é ainda território pouco explorado, mesmo com tantas discussões em torno deste conceito. Quais ideias estão servindo para o fundamento reflexivo do que é ou não afetividade se mostra um questionamento pertinente à Psicologia, um convite para se pensar os aspectos ontológicos e epistemológicos desta ciência.

No século XVII, com a sobrevaloração da razão como única forma de conhecer o humano, passou-se a desprezar uma condição essencial na formação do ser humano humanizado ${ }^{1}$. Em meio à ênfase racionalista, um pensador expõe o abandono do caráter afetivo da existência num sentido propositivo, revelando a urgência de conhecer as afetações do corpo na construção das relações em sociedade.

Frente uma filosofia que desconsiderava o corpo afetivo, os sentidos e as emoções na constituição do sujeito, o significado dos afetos vai ser resgatado por Espinosa, quando este diz: "quero voltar àqueles que preferem detestar ou ridicularizar as afecções e as ações do homem a conhecê-las..., e que queira demonstrar por raciocínio rigoroso o que eles não cessam de proclamar contrário à Razão, vão, absurdo e digno de horror" (ESPINOSA, 1983, Ética III, Preâmbulo, p. 175).

As indagações colocadas pelo filósofo são recuperadas na literatura psicológica por autores emblemáticos dentro deste campo do conhecimento: Vigotski expõe em sua teoria das emoções a contradição presente nas psicologias de sua época que tinham uma leitura do afeto com base em princípios cartesianos. Freud, na psicanálise, ao desenvolver uma teoria da psiquê elabora que os afetos são resultantes dos impulsos inconscientes (COSTA; PASCUAL, 2012; MACHADO et al., 2011; MAGIOLINO; SMOLKA, 2010; VIGOTSKY, 2004). Como um estudo filosófico que tem como fundo uma lógica dedutiva, o exame que Espinosa faz das emoções torna-se contribuição à própria Psicologia na constituição de um quadro teórico das emoções.

É digna de nota que, embora não tão frequente na Psicologia, salvo discussões recentes no campo da Psicologia Social da Escola de São Paulo, mais especificamente através do Núcleo de Pesquisa

1 O ser humano torna-se humanizado por meio do processo relacional e dialógico entre subjetividade e objetividade como condição da constituição de um ser humano que interage no e com o mundo, transformando-o e ao mesmo tempo sendo transformado por este (EUZÉBIOS FILHO; GUZZO, 2009). 
Dialética Exclusão/Inclusão Social - NEXIN, PUC-SP, a compreensão espinosana das emoções lança uma revolução no campo do pensamento psicológico.

Recuperando o movimento espinosano percebe-se que a Psicologia tem se apropriado de diferentes maneiras do que é o afeto. No que diz respeito ao afeto em Espinosa, questiona-se: qual é a apropriação da ciência psicológica sobre o afeto espinosano? Nesse sentido, indaga-se como o tema "afetividade" se expressa na práxis psicológica através de uma revisão na literatura disponível em base de dados. Considera-se, pois, a dimensão afetiva como parte fundamental no processo de constituição da existência do ser humano. O termo "homem" ou "ser humano" será utilizado no decorrer do texto em respeito à literatura filosófica, mas, em alguns momentos podem aparecer variações como "sujeito" ou "indivíduo", pertinentes ao contexto da psicologia.

Primeiramente, recupera-se a teoria de Espinosa sobre os afetos e demais conceitos articulados quanto a esta compreensão. Para conhecermos no próprio autor destaca-se a concepção de conatus, afecção, afeto, desejo, potência e paixão, conceitos essenciais na teoria espinosana. Devido a profundidade do pensamento deste filósofo e como um estudo preliminar, seria inviável discorrer sobre todas as concepções inerentes a sua teoria dos afetos.

Num segundo momento, fez-se uma revisão bibliográfica com fins ao uso da teoria espinosana pela psicologia. Para isto, considerou-se os seguintes critérios: identificação do uso/menção das palavras-chave no texto de apresentação dos trabalhos publicados em base de dados, averiguação e seleção da literatura levantada.

Por fim, discorre-se sobre as formas de utilização dos conceitos espinosanos, como estão sendo abordados e discutidos dentro da literatura recuperada. A análise é feita a partir de categorias eleitas como "uso casual" (apenas menção), e "uso sistemático" (apropriação de um ou mais conceitos), também são considerados os conceitos que receberam maior atenção ou citação e quais as áreas que buscam em Espinosa uma contribuição às suas reflexões.

\section{MÉTODO}

O avanço da ciência se dá por meio de dúvidas e perguntas que se transformam conforme diferentes tempos e momentos de acordo com cada contexto histórico. Se a ciência ou conhecimento avança pela dúvida e pela pergunta, como fruto de um processo de investigação, toda pesquisa é feita por aquele que pergunta e assim é construída pela narrativa dada como resposta à esta pergunta (PROST, 2008). A história visa compreender o homem no tempo, ela é busca, portanto, escolha daquele que pesquisa num universo extenso de fatos $(\mathrm{BLOCH}, 2001)$. Logo, é entender que os eventos do passado nunca se alteram, mas a compreensão sobre os fatos se modifica a cada nova pergunta e os documentos só falam quando sabemos perguntar. Assim, este artigo visa responder a seguinte pergunta norteadora: qual é a apropriação da psicologia sobre o afeto espinosano?

Para tanto, produziu-se uma revisão bibliográfica das produções disponíveis em base de dados a partir de uma análise histórica do tipo documental, buscando descrever os usos da teoria espinosana pela Psicologia nos artigos pesquisados. Retomamos o conceito de documento como quaisquer materiais escritos que possam ser usados como fonte de informação (PHILLIPS, 1974). Nesse sentido, o estudo configura-se como uma pesquisa documental, incluindo a revisão bibliográfica, delineada pela organização e interpretação desses documentos de acordo com o direcionamento do objeto investigado (PIMENTEL, 2001).

Na revisão bibliográfica buscou-se pelo uso da teoria de Espinosa pela Psicologia. Para isso optou-se em não demarcar cronologicamente, como também não houve recorte de região no intuito de verificar todas as localidades em que a temática pesquisada poderia ser abordada. A busca pelos artigos se deu pelas palavras-chave - afeto, afetividade, teoria dos afetos, psicologia e Espinosa - seguido de averiguação da literatura levantada e seleção somente de artigos que correspondiam a demanda da pesquisa. 
O levantamento foi realizado em bases de dados como Portal de periódicos CAPES, BVS-PSI, Scielo, ABRAPSO, Revista Psicologia \& Sociedade, Revista Psicologia: Ciência e Profissão, Conselho Federal de Psicologia, Conselho Latinoamericano de Ciências Sociais (CLACSO) e Rede de Revistas Científicas da América Latina e Caribe, Espanha e Portugal (REDALYC). Numa primeira triagem foram levantadas 249 produções a partir da combinação dos descritores anteriormente citados - desde idos de 1980 até atualmente -, em seguida, após a leitura dos resumos, este corpus foi redimensionado para 16 artigos - datados de 2006 a 2016. Considerou-se como critério de identificação o uso/menção dos descritores nos resumos e a diversidade temática, visto que, houve repetição da mesma temática inúmeras vezes, recaindo em sua maioria sobre a questão educacional, escolar, infantil, ensino, aprendizagem.

É importante sublinhar que dentre as produções levantadas, a diversidade da utilização do tema acerca da afetividade se distribuiu - de maneira díspar - entre as seguintes esferas: educacional/ docência/alunos; etnia; sexualidade; relações de trabalho; política; neurociência; cognição; cultura; adolescência; conflitos interpessoais; sofrimento ético-político; doenças degenerativas; psicologia ambiental; adoção; religião; odontologia para bebês; padrões de comportamento; exploração lúdica; psicocardiologia e doenças coronárias; terapia familiar; infância e violência; saúde em geral.

O material de análise comporta todas as informações recolhidas através dos artigos que fazem referência à Espinosa e/ou sua teoria para fins de análise documental. Nestes artigos foi possível conhecer as ideias, a compreensão e a abordagem feita à teoria espinosana, assim como ao próprio filósofo. O objetivo foi investigar como a teoria de Espinosa é utilizada dentro da Psicologia em sua produção científica. Para isto, realizou-se um trabalho analítico descritivo, verificando a partir da aparição de Espinosa ou de seus conceitos como se deu esse uso em cada uma das literaturas recuperadas.

O procedimento para a análise do conjunto desses artigos partiu da identificação do uso/menção das palavras-chave no decorrer de todos os textos, primeiramente grifando todas as aparições espinosanas, o nome, citações, ideias sintetizadas, vinculação a outro autor, conceitos e referência a seu método filosófico. Se fez mapeamento da presença espinosana dentro dos artigos para em seguida iniciar a análise de como essas aparições são abordadas. Assim, elegeu-se três critérios específicos pelos quais foi possível avaliar de que modo a psicologia se apropria da teoria de Espinosa. São eles: a) distinção entre usos casuais e usos sistemáticos da obra de Espinosa; b) conceitos espinosanos que recebem maior atenção ou citação; c) áreas que buscam no autor subsídios teóricos-reflexivos.

\section{ESPINOSA: O FILÓSOFO DO SÉCULO XVII E SUAS REFLEXÕES ACERCA DOS AFETOS/EMOÇÕES}

Espinosa (1632-1677) ao descrever a afetividade humana em sua obra germinal, intitulada Ética, realiza um mapeamento e uma nova e ampliada perspectiva epistemológica sobre a natureza e as forças das afecções, mas, sobretudo, uma nova maneira de pensar sobre estas. "Uma afecção, chamada paixão da alma (animi paterna), é uma ideia confusa pela qual a alma afirma a força de existir, maior ou menor do que antes, do seu corpo ou de uma parte deste [...]" (ESPINOSA, 1983, Ética III, Definições, p. 221).

O termo Ética, utilizado na obra de Espinosa, de nenhuma forma se refere à obrigações e deveres ligados à moralidade, mas sim, de modo contundente, o termo se traduz como a manifestação do próprio ser do homem, exatamente como ele é, em sua maneira de ser, como um todo em funcionamento, uma totalidade. Conforme Chauí (1983, p. 14):

Para o senso comum Ética e Moral são uma só e mesma coisa: doutrina dos deveres do homem. A primeira coisa que espanta o leitor de Espinosa é que este separe Ética e Moral, colocando esta última junto a Religião e definindo ambas, Moral e Religião, como sistemas que impõem certos deveres ao homem. A Ética nada tem a ver com os deveres ... . A Ética é a definição (ou apresentação) do ser do homem tal como ele é, e demonstrando por que o homem é tal como é.... Espinosa recupera o sentido grego de ethos: modo ou maneira de ser. 
Sawaia (1998, p. 122-123), salienta a acepção de Ética em Espinosa, “sua ética é ontológica e é histórica, refere-se ao movimento de constituição do homem como potência de liberação .... Também, é epistemologia, porque é ideia correta das afecções do corpo e, por ser afecção do corpo, é emoção, desejo e relação".

Para o filósofo, o corpo é o meio material através do qual, abre-se a possibilidade para que a mente conheça as coisas do mundo e, assim, através de imagens, possa elaborar conhecimento. Como nos aponta Sawaia (2009, p. 366), Espinosa escreveu "um verdadeiro tratado das emoções..., no qual demonstra de forma geométrica que a vida ética começa no interior dos afetos, e não contra eles". Nas palavras da autora (1998, p. 122):

trabalhou na fronteira entre as cisões rígidas, promovidas pela ciência, entre mente/corpo, singular/ universal, egoísmo/solidariedade. Ele é um racionalista que analisa a ética como emoção, é um individualista que pensa a ética pela alteridade, um filósofo da imanência... um materialista que permite entender como a 'ordem dos significados está incluída na ordem da vida'.

Ao falar sobre a dimensão afetiva do humano, Espinosa a concebe como parte constituinte deste ser e não como vícios do homem e coisas que estão fora da Natureza, o filósofo não adere a concepção, difundida na época, onde mente (alma) e corpo são tomados separadamente - o que reforçou a perspectiva de que o único meio pelo qual se poderia conhecer uma verdade seria através da razão -, mas contrariamente, ele destaca a afetividade humana como parte de sua natureza, digna de estudo e conhecimento:

Nada acontece na natureza que possa ser atribuído a um vício desta; a Natureza com efeito, é sempre a mesma; a sua virtude e a sua potência de agir são unas e por toda parte as mesmas ... a via reta para conhecer a natureza de todas as coisas, quaisquer que elas sejam. Portanto, as afecções..., consideradas em si mesmas, resultam da necessidade e da mesma força da Natureza que as outras coisas singulares ..., têm propriedades determinadas tão dignas do nosso conhecimento como as propriedades de todas as outras coisas ... (ESPINOSA, 1983, Ética III, p. 175).

Assim, Espinosa coloca em pauta um sujeito constituído por inteiro, sem rupturas ou dualismos entre corpo e mente, que, ao mesmo tempo em que é constituído pela sociedade, também tem o poder de constituí-la, ou seja, assim como é afetado pelos outros, também possui a capacidade de afetar esses outros. "Considerei também as emoções humanas ... como propriedades da natureza humana: maneiras de ser que lhe pertencem como o calor e o frio, a tempestade, a trovoada e todos os meteoros pertencentes à natureza atmosférica" (ESPINOSA, 1983, Trat. Político Cap. I § 4, p. 306).

O pensamento de sua época fundamentava-se, principalmente, nas Ciências Exatas e Ciências Físicas, demarcado pela efervescência das chamadas Revoluções Científicas, desconsiderando ou excluindo as emoções como fenômeno constituinte do homem. Estas eram vistas como algo negativo, um empecilho para a construção do conhecimento, eram consideradas causa de desordenação do sujeito, designando-as como coisas externas e profanas, coisas do mundo e não do homem, mas para Espinosa, negar o afeto é negar a existência em sua totalidade e capacidade de potência:

no pensamento espinosano não existe lugar para a existência de planos ou desígnios exteriores ... a ação humana é regulada imanentemente por sua própria condição de ser parte da Natureza. O seu racionalismo se dá na plena confiança da potência de conhecer da razão, que não é, em nenhuma hipótese, entendida como a contraparte das emoções. (BRANDÃO, 2008, p. 69).

Desta forma, compreende-se que, quanto mais se concebe e se toma o sujeito em sua totalidade, sem dissociações, tanto mais serão possíveis os caminhos de acesso e a produção do conhecimento das 
verdades. Espinosa postula que a verdade está imanente ao conhecimento que se produz, é indissociável deste, não sendo necessário, portanto, qualquer prerrogativa externa (CHAUÍ, 1983).

Por meio das afecções que o corpo sofre, a mente pode produzir - através das imagens - ideias que podem ser adequadas ou inadequadas. A imagem, para Espinosa, é a primeira etapa em que se dá o conhecimento e é por meio das imagens que o sujeito faz das afecções sofridas pelo corpo que a mente conhece o mundo, imagens estas que não são como meras reproduções dos objetos, mas sim a imagem que este objeto nos desperta (SAWAIA; SILVA, 2015).

Por ideias adequadas entende-se aquelas que são concebidas de forma autônoma, relacionando-se com forças externas, mas sem se destruir ou se submeter a elas, é quando sua causa ou origem é conhecida, aumentando, portanto, seu conatus, ou seja, sua força, sua potencialidade de existir. Por ideias inadequadas entende-se aquelas que são dominadas e determinadas pelas causas externas, diminuindo assim, a força do conatus.

Tal força, para Espinosa, é intrínseca a todo indivíduo, a todo ser humano, uma força que o move, de gênese positiva, o lança adiante e ativo em busca de sua própria conservação, seu mantenimento enquanto Ser na vida, é o ímpeto para a existência. Entretanto, essa força e movimento não se dão somente em função da conservação da vida orgânica, mas sim como a expansão do corpo e da mente, em um movimento de perseverar pela própria existência, na busca pela liberdade e pela felicidade, fatores elementares para a constituição do Ser (SAWAIA, 2009).

Aqui reside a premissa de quão elementar e necessário se faz para o indivíduo tecer contato com o outro, relacionar-se, perseverar em sua própria existência através da existência do outro:

O seu princípio universal de que "toda coisa, enquanto está em si, se esforça por perseverar no seu ser” demonstra qual natural é que os indivíduos se relacionem uns com os outros, buscando sua conservação e expansão, ao mesmo tempo em que afetam e são afetados. Espinosa não enxerga a realidade estaticamente, isto é, como se os entes (humanos ou não) permanecessem sempre no mesmo estado. Ele é partidário de uma compreensão dialética. ... defende que todas as coisas são dotadas de uma potência para a vida. Longe de ser uma finalidade, o conatus é, por assim dizer, uma força ou esforço positivo, intrínseco em todos os seres ... (BRANDÃO, 2008, p. 81).

Por meio da dimensão afetiva é possível acessar o conhecimento de uma certa verdade, de uma ideia e, por conseguinte, o conhecimento dos outros, das coisas e de si mesmo. A dimensão afetiva está intrinsecamente ligada ao pensamento e ação do indivíduo no mundo, dando-se muito mais que um termômetro de sua potência, mas, sobretudo, como elemento fundamental da existência humana, necessária para sua autoconservação e seu agir no percurso da vida.

Em sua singularidade, o ser humano é constituído pelas afecções, que se dão pela via do apetite e do desejo, incutidos em sua natureza como potencialidade de ação e de existência do Ser, a mercê das forças e pressões de causas externas, assim como, das causas internas, por onde também ele se constitui, como apropriação de sua natureza e como instalação de sua sociabilidade e política (SAWAIA, 1998, p. 123).

Quanto mais o Ser se coloca desejoso, tanto mais são as vias de afecções e, o conatus, enquanto potência imanente do indivíduo, que expressa sua singularidade, "pode aumentar ou diminuir, dependendo da maneira como cada singularidade se relaciona com outras ao efetuar seu trabalho de autoconservação" (CHAUÍ, 2002, p. 9). O conatus se dá de forma singular como potência a cada indivíduo, ainda que numa relação contínua com o mundo, a natureza e outros conatus. Isso revela a condição imanente da qual a substância do Ser pode aumentar ou reduzir, mostrando como cada um persevera na sua existência, ou seja, no seu conatus.

A diminuição da intensidade do conatus se dá no momento em que a singularidade do indivíduo é afetada por outras de certo modo que a faça se converter em uma singularidade totalmente dependente das 
outras, entretanto, a força do conatus aumenta sua intensidade ao modo que, ao ser afetada por outras e também afetá-las, a singularidade não perde sua independência nem sua autonomia (CHAUÍ, 2002, p. 9).

Aumentar ou diminuir o conatus, ou seja, a força e a potência interna do indivíduo, que é imanente a ele, é também impactar da mesma forma sobre o desejo e o apetite pelo existir, pela autoconservação. É também como se referir ao aumento ou diminuição de seu próprio movimento no mundo e na vida, em outras palavras, o aumento ou diminuição do conatus, pode ser também o aumento ou a diminuição da própria existência do indivíduo.

Essa força nomeada por Espinosa de conatus, como visto anteriormente, configura-se de forma multifacetada e o filósofo também vai chamá-la de vontade - quando referido a mente -, de apetite quando referido ao corpo -, e de desejo (cupiditas) - quando este apetite é consciente:

entre o apetite e o desejo não há nenhuma diferença, a não ser que o desejo se aplica geralmente aos homens quando têm consciência do seu apetite e, por conseguinte, pode ser assim definido: o desejo é o apetite de que se tem consciência. É, portanto, evidente, em virtude de todas estas coisas, que não nos esforçamos para fazer uma coisa que não queremos ... (ESPINOSA, 1983, Ética III, Prop. IX, Esc.).

Para Espinosa, exatamente por possuir esta força e potência de conservação, via de acesso ao devir do desejo, que move o ser e que lhe é imanente, não há nenhum ser que almeje ou busque pela própria destruição, a não ser, por algo externo que lhe exerça padecimento e destruição, "nenhuma coisa pode ser destruída, a não ser por uma causa exterior ... as coisas são de natureza contrária, isto é, não podem coexistir no mesmo sujeito, na medida em que uma pode destruir a outra" (ESPINOSA, 1983, Ética III, Prop. V, p. 180).

Assim, sob a perspectiva de positividade dos afetos e, jamais como negatividade do ser, a teoria proposta por Espinosa, demonstra que, imprescindivelmente, tudo passa pela dimensão afetiva, pelas afecções sofridas pelo corpo e os afetos nele gerado:

A proposição que apresenta a existência do conatus é, por assim dizer, a base que fundamenta toda teoria da afetividade, da ética e da política espinosanas, posto que, ao afirmar que as coisas têm uma potência de agir, e, por outro lado, ao negar a existência da pulsão de morte, fica evidente a positividade ontológica do seu pensamento... (BRANDÃO, 2008, p. 81).

A teoria de Espinosa nos fala tanto das afecções (affectio), quanto dos afetos (affectus), de maneiras distintas, porém, deparamo-nos com a utilização de tais termos como se possuíssem a mesma definição e a mesma função, como sendo a mesma coisa, entretanto, os termos distinguem-se entre si, "por afecções entendo as afecções do corpo, pelas quais a potência de agir desse corpo é aumentada ou diminuída, favorecida ou entravada, assim como as ideias dessas afecções" (ESPINOSA, 1983, Ética III, Definições, p. 176).

Assim, as afecções são afetações sofridas pelo corpo em sua totalidade, na própria conduta, no próprio jeito, bem como no modo de percepção e perspectiva sobre a realidade. A respeito da designação de afeto, este se dá como fruto da afecção sofrida, sob a configuração de emoções e sentimentos, por meio dos quais, a potência pode ser aumentada ou diminuída:

Ora, o que se passa em nosso corpo - as afecções - é experimentado por nós sob a forma de afetos (alegria, tristeza, amor, ódio, medo, esperança, cólera, indignação, ciúme, glória) e por isso não há imagem alguma nem ideia alguma que não possua conteúdo afetivo e não seja uma forma de desejo. São esses afetos, ou a dimensão afetivo-desejante das imagens e das ideias, que aumentam ou diminuem a intensidade do conatus. Isto significa que somente uma mudança na qualidade do afeto pode nos levar ao conhecimento verdadeiro, e não o contrário, e é por isso que um afeto só é vencido por outro mais forte e contrário. (CHAUí, 2002, p. 10). 
Os afetos, enquanto ideias que realizamos das afecções experienciadas pelo corpo, possuem intensidades diferenciadas que são fonte de enfraquecimento ou de fortalecimento do conatus. Consequentemente, afetos fracos promovem o enfraquecimento da existência e do agir do indivíduo na vida, já os afetos fortes são fortalecedores da potência, da força, ou seja, o conatus será fortalecido.

Por afetos fracos entende-se os que são decorrentes da tristeza - paixões tristes, passividade e submissão às forças externas -, os que fazem com que o ser sinta sua potência diminuída, sem força de ação em sua existência em decurso de uma causa externa; quanto aos afetos fortes, entende-se por aqueles que nascem da alegria - paixões alegres -, ou seja, daqueles sentimentos que aumentam e fortalecem o conatus também em decurso de causa externa, porém, sem dominação ou submissão a estas causas, também são tomados como ação quando a causa é interna e sua força de potência depende somente de si (CHAUÍ, 2002).

São chamados afetos primitivos ou também paixões originais somente três afetos, a alegria, a tristeza e o desejo, assim, todos os outros tipos de afetos são provenientes destes primeiros. A alegria é estar de acordo com nossa natureza e conservação da existência, aumenta a ação do sujeito no mundo; a tristeza o lança no sofrimento, perde a autonomia e se torna passivo, dominado; e o desejo é a força propulsora do Ser em direção e em relação ao mundo:

Três são as paixões originais: alegria, tristeza e desejo. As demais derivam-se destas. Assim, da alegria nascem o amor, a devoção, a esperança, a segurança, o contentamento, a misericórdia, a glória; da tristeza surgem o ódio, a inveja, o orgulho, o arrependimento, a modéstia, o medo, o desespero, o pudor; do desejo provém a gratidão, a cólera, a crueldade, a ambição, o temor, a ousadia, a luxúria, a avareza. No caso do desejo, podemos ter paixões tristes (como a crueldade, a ambição, a avareza) ou alegres (como a gratidão e a ousadia). (CHAUÍ, 2000, p. 449).

A teoria espinosana compreende que as paixões não são boas e nem más, são sim propriedades da natureza, por isso podem afetar de diversas maneiras até mesmo por uma só coisa, ou seja, o sujeito pode se afetar de formas diferentes em relação a uma mesma coisa que o afeta, visto que, a qualidade de ser boa ou má é facultada a este afeto/paixão no processo de apreensão que o sujeito realiza deste afeto. Assim, a vários afetos ao mesmo tempo pode-se imprimir positividade ou negatividade, fenômeno este que abre um convite a práxis psicológica em relação a dinâmica da afetividade humana, sua gênese e seus desdobramentos.

Ao falar de como podemos ter a força de potência aumentada ou diminuída, Espinosa, destaca a importância dos bons e maus encontros, "constituídos historicamente nas relações entre os corpos" (SAWAIA, 1998, p. 126), através dos quais, ocorrem as afecções que sofremos. Depreende-se aqui, que a afetividade em Espinosa é material elementar para se pensar o ser humano e o processo de construção de sua existência e ação no mundo. A perspectiva que Espinosa demarcou fala à Psicologia sobre a complexidade de um sujeito inteiro, que se constitui, se transforma e tem o poder de transformação por meio dos encontros e das experiências com os outros e com a vida.

\section{A APROPRIAÇÃO DA PSICOLOGIA SOBRE OS CONCEITOS ESPINOSANOS}

Com a análise de artigos publicados no campo da Psicologia, percebe-se que as ideias de Espinosa fundamentam-se nos conceitos de afeto, afecção, conatus, potência, desejo e paixão. Logo, a forma como estes vêm sendo discutidos ou abordados dentro deste campo se dá pelo seguinte movimento: os usos casuais e os usos sistemáticos dos conceitos espinosanos. Além de observar como a referência pessoal ao autor e a sua filosofia é apresentada na literatura analisada.

Os artigos foram analisados da seguinte forma: como "uso casual", faz-se a compreensão de apenas "menção" do filósofo e sua teoria, ou seja, obras nas quais o nome de Espinosa, o conceito ou ideia sobre 
afeto/afetividade são utilizadas mas sem uma discussão ou reflexão das implicações epistemológicas. Ainda assim, quanto ao uso casual, considerou-se as ideias que desempenharam um papel importante, mesmo sendo somente uma menção, ou seja, quando o autor trabalhou somente um conceito, mas a partir dele elaborou uma reflexão dentro do contexto em que é utilizado, fazendo um recorte conceitual.

No que diz respeito ao "uso sistemático", não se refere necessariamente a fazer uso de todos os conceitos, pois é possível, a partir de somente um conceito, tomá-lo como ponto de partida para uma reflexão, ou seja, dialogar com este conceito ao longo de toda elaboração textual, produzindo aproximação epistemológica com a teoria e o sentido simbólico trazido por Espinosa. Considerou-se também como uso sistemático alguns conceitos ou ideias colocadas no texto e que tinham extensão explicativa nas notas de rodapé. Conceitos como afeto e afecção, por exemplo, em determinado momento foram conceituados de forma reduzida, mas são utilizados como base para discorrer sobre o tema central. Também ocorreu o uso de somente um conceito espinosano que a priori apareceu ao lado da perspectiva de outros autores, mas que em seguida ganhou reflexão particular. Em outra ocasião, Espinosa é mencionado poucas vezes ao longo do texto, mas é trazido para a discussão em momentos específicos onde é feita uma elaboração sobre o que é citado do filósofo.

Analisou-se, também, quais conceitos recebem maior atenção ou citação nos artigos escolhidos. Notou-se dentro desta averiguação o uso acentuado do conceito de afeto/afetividade/dimensão afetiva, seguido do conceito de conatus, encontro, paixão, afecções e imaginação. Outros conceitos espinosanos apareceram de forma isolada e não foram comuns na maioria dos textos, por isso não são citados neste estudo.

A seguir descreve-se os conceitos espinosanos mais utilizados e como são trabalhados, referência pessoal do autor e referência à sua filosofia dentro dos artigos escolhidos: a) Variações entre afeto, afetividade, dimensão afetiva - mediador da interação social; afecção simultânea do corpo e da mente, como ideia e como o que se passa no corpo; expressão musical do sofrimento ético-político; fenômeno da ordem do encontro; constituinte do pensar e do agir humano; indissociável da condição humana; b) Conatus - esforço em viver; ação do homem em direção a algo; impulso; apetite; vontade; força para se conservar; c) Encontro - experiência humana e acontecimento social; possui a potência de fazer emergir algo desconhecido do sujeito; relação de composição e decomposição; fatores de deflagração da potência individual; d) Paixão - algo que está envolvido no processo de afetação e na relação entre os sujeitos (pelo encontro); constitutiva da natureza humana; ideias ilusórias; passividade; e) Afecções - intersubjetividades que constituem o ser humano e que se dão nos bons e maus encontros; atividade e passividade; f) Imaginação - necessidade para manter o conatus, resistir a paixão e substituí-la (potência da inteligência ou potência da liberdade humana); imagens das afecções.

Espinosa é referido nos artigos analisados como: a) Influência direta na contribuição da perspectiva de outros autores e suas teorias; b) Filósofo monista; c) Apóstolo da razão; d) Pensador das relações, ao postular sobre os encontros; e) Pensador e teórico que deu base para a origem de alguns conceitos em Vigotski; f) Idealista e contraditório ao materialismo de Marx - postulando uma natureza racionalizada e não uma natureza materializada; g) Racionalista, mas não dualista.

A filosofia de Espinosa aparece como: a) Panteísta; b) Crítica ao dualismo mente/corpo; c) Antagônica à perspectiva filosófica de Descartes; d) Teoria predecessora adotada por muitos estudiosos na construção da teoria histórico-cultural, especialmente Vigotski; e) Teoria que passou despercebida para as ciências modernas, não se tornando um legado como a lógica cartesiana se tornou; f) Método para se chegar ao conhecimento perfeito, que seria a chave para a libertação das afecções que diminuem o conatus; g) Método que segue o modelo da geometria euclidiana; h) Compreensão de desdobramentos éticos-políticos da paixão; i) Fundamental para a compreensão das afecções e da atração entre os corpos; j) Filosofia monista que é antídoto para o dualismo de Descartes; k) Superação da visão das emoções e imaginação como opostas à razão e separadas do pensamento; 1) Marco orientador para os sujeitos, lembrando-os que viver significa muito mais que apenas sobreviver; m) Filosofia para tornar o homem um ser ativo; n) Teoria que se afasta de uma 
explicação mecanicista, mente e corpo atuando juntos no mesmo evento; o) Filosofia que concebe a relação de corpo, mente e conatus; p) Filosofia da alegria.

De modo geral, a análise do conteúdo dos artigos mais relevantes que trabalham com a teoria ou algum conceito específico em Espinosa demonstram que: a) A teoria espinosana é desbravadora para sua época, momento no qual havia a predominância de um racionalismo puro e extremo, descartando as emoções como condição constituinte do ser humano; b) A filosofia de Espinosa é uma ruptura com o pensamento de Descartes, demarca a unificação corpo/mente e pensa a dimensão afetiva como fator indissociável da condição humana; c) Espinosa é o teórico mais associado a Vigotski, sendo atribuído ao filósofo a contribuição e influência sobre os pensamentos e construção da teoria histórico-cultural do psicólogo. As inquietações espinosanas serviram de inspiração a Vigotski, deixando a ele três grandes legados para serem discutidos: intelectualismo; ferramentas intelectuais e determinismo; d) O determinismo espinosano está conexo com a liberdade, o homem está em liberdade quando possui ideias adequadas, não sendo controlado pelas paixões, suas determinações são causas de si mesmo, de sua própria escolha, ele se autodetermina; e) As temáticas servidão e liberdade aparecem como inquietação do filósofo, sobre a qual ele procurou entender como o ser humano luta pela servidão como se fosse pela própria liberdade, uma liberdade que é ilusória. Espinosa encontra a resposta na dimensão afetiva vivida pelo homem; f) Ao falar de liberdade ressalta-se a importância de se falar da ontologia espinosana, posto que a liberdade é de ordem ontológica e não meramente livre arbítrio. Sendo possível pensar sobre o valor dessa liberdade e também a coibição da mesma na realidade de pessoas que vivem na pobreza; g) A relevância do sistema afetivo/criativo na produção da desigualdade social, visando o planejamento de uma práxis ético/estética para a transformação social; h) A composição do processo psicológico político que se dá através da relação entre a desigualdade social e as repostas afetivas dos sujeitos que vivem nesta condição; i) O conatus é a força de vida do sujeito, a força que o impulsiona para a conservação de seu próprio ser, sua força interna e positiva, pois o impele para a vida e não para a morte; j) A potência comum é considerada como mais poderosa quando comparada ao conatus individual, sinalizando que é o desejo do útil comum que compõe a gênese da sociedade e que o comum é fortalecimento para o conatus de cada indivíduo; k) A partir da ideia de encontro e unificação corpo/mente em Espinosa, amizades feitas e mantidas através da internet ganham validade e dimensão afetiva. São novas formas de relações sociais, mas também passíveis de afecções e da força dos afetos. O corpo pode ser afetado de diversas maneiras e sua potência pode ser aumentada ou diminuída, segundo a premissa espinosana; 1) Novos espaços de encontros são espaços de compartilhamentos diversos, por isso se tornam meios para novas formas de afetação dos corpos, que são afetados pelas ideias; m) A construção de um pensamento filosófico que resgata nas concepções espinosanas de imagem, imaginação e emoção, base para seus estudos sobre a produção imaginária como condição fundante e explicativa da especificidade humana; $n$ ) A afetividade dentro da produção musical, destacando afetividade enquanto expressão afetiva do sofrimento ético-político vivido por pessoas em situação de desigualdade social. A dimensão afetiva é parte constituinte do pensamento e da ação do sujeito, sendo expressada através das composições musicais; o) Existe um contraponto a ser feito quanto a menção de Espinosa como idealista e possível base para um pensamento psicologizante ao pontuar que tudo isso se dissolve em seus fundamentos ontológicos, onde não há primazia para o corpo ou a mente, o que leva o homem à ação. Sinalizando que sua filosofia não tem somente a função de apreender o mundo e pensá-lo, mas pensar também o homem em atividade, pensar sobre o processo de tornar-se um ser ativo.

Apenas em 7 artigos foi possível constatar o uso casual do nome ou teoria espinosana, na maioria das vezes fazendo um sobrevoo da relação de Espinosa com o afeto e uma elaboração sutil dos termos afeto, potência e encontro. As ideias espinosanas não ganham grande proporção, aparecendo como ilustração ou como reforço para outras perspectivas utilizadas.

Frequentemente denota-se Espinosa como autor que complementa a ideia de outros autores, não havendo apresentação sobre quem foi o filósofo ou a intencionalidade da teoria por ele elaborada. 
Algumas vezes o afeto é conceituado primeiramente através de outros autores e posteriormente por Espinosa, como pano de fundo em meio a outras considerações teóricas.

Outrora é dada ao filósofo a autoria de determinado termo utilizado no texto seguido de uma citação retirada da obra Ética, mas que fica isoladamente sem elaboração reflexiva. De forma semelhante, também, aparece o uso do conceito de conatus, aumento ou diminuição de potência, colocados em parágrafo único, de forma isolada e sem aprofundamento, neste caso sem citações.

Seguindo esse modelo de parágrafo único, a teoria espinosana aparece em determinado momento como introdução geral de suas ideias, passando pelos conceitos de desejo como sendo a própria essência do homem; conatus como impulso; amor como alegria junto a ideia de causa externa e ódio como tristeza também junto a uma ideia de causa externa. Ainda de forma casual (menção), e seguindo o mesmo modelo de parágrafo contatou-se o uso das concepções de natureza naturans, natureza naturata e conatus.

Espinosa aparece ainda em certo momento apenas como referência para confirmar a inspiração de Vigotski em uma solução monista, posteriormente não há uso ou menção do filósofo e nenhum de seus conceitos. A perspectiva teórica de Espinosa também aparece como pano de fundo para comparação ou fundamento na formulação da teoria de outros autores, entretanto não houve aprofundamento reflexivo no que diz respeito à teoria espinosana.

Assim, algumas leituras só fazem menção a Espinosa uma única vez, ao se referir sobre a temática dos afetos e o quanto ela é de interesse de diversos teóricos, como autor da modernidade que destacou a potência dos afetos ou ainda como menção entre um conjunto de autores para fundamentar brevemente o propósito da dimensão afetiva.

No mais, os afetos foram trazidos para a discussão a luz de outros autores e suas teorias, também foram mencionados como qualidade de vínculo entre os sujeitos, como relação de proximidade que abarca atitudes positivas e propicia o aprendizado. Uma única vez as emoções foram trazidas como processo psicossomático encerrado somente ao corpo ou à alma, sob a perspectiva de outro autor, contrapondo-se integralmente a perspectiva espinosana.

Os outros 9 artigos fizeram uso sistemático da perspectiva espinosana num cenário onde Espinosa e sua teoria foram protagonistas dentro da elaboração reflexiva. Os conceitos espinosanos são colocados como pressupostos fundamentais para a reflexão sobre: dimensão afetiva e suas especificidades, processo de subjetividade, produção imaginária na constituição do Ser, aspectos cognitivos, corpos se afetam, desenvolvimento humano, afetividade musical, sofrimento ético-político, desigualdade social, em geral temas que envolvem a transformação do sujeito de forma coletiva ou singular.

Mesmo quando única ou poucas as menções feitas a Espinosa, denota-se ao longo desses artigos a busca pela contribuição reflexiva do filósofo na construção de um pensamento ou como inspiração para outro autor que fala sobre afeto e outros conceitos espinosanos. Alguns textos discorrem integralmente sobre a trajetória de outros estudiosos, mas dão a Espinosa a autoria precursora sobre o tema afetividade ou utilizam sua teoria para melhor compreender o outro autor.

Como resultado constatou-se que 7 (43,75\%) dos artigos fazem uso casual do nome ou teoria de Espinosa. Grande parte realiza uma visão geral e resumida sobre a correlação entre Espinosa e o afeto/ afetividade/dimensão afetiva, passando ligeiramente pelos conceitos de afeto, potência e encontro sem grande aprofundamento de sua perspectiva. Os 9 (56,25\%) artigos restantes destacaram o uso da teoria, da referência pessoal ou mesmo de um ou mais de seus conceitos elaborando reflexão sobre estes.

No decorrer da revisão realizada, surgiram inúmeras produções que abordavam o tema afeto/ afetividade, mas quando analisadas mais detalhadamente percebeu-se que não atendiam aos critérios balizadores desta pesquisa. A maioria não apresentava nenhum tipo de ligação com a teoria espinosana, apenas citavam ou discorriam sobre o afeto dentro dos moldes do senso comum, ou seja, como atenção, proximidade, carinho, entre outras demonstrações que derivam do processo afetivo, mas não podem ser caracterizadas como sendo o próprio afeto, em forma unitária, reduzida e determinada. 
Ao falar em afeto considera-se que a amplitude de tópicos que esta dimensão abrange se dá como parte fundante em cada relação e tecimento social e, por se tratar de algo indissociável do ser, torna-se essencial para o estudo do humano e suas peculiaridades, sobre o processo de transformação deste sujeito - geometricamente desenhado na teoria espinosana - desde sua gênese até sua ação no mundo.

Em relação as áreas que buscam em Espinosa desde uma contribuição reflexiva à uma ilustração ou pano de fundo para suas ideias, encontra-se significativamente a Sócio-Histórica ${ }^{2}$ e Histórico-Cultural, seguidas por outras como a Educacional, Psicologia do Desenvolvimento, Psicologia Clínica, Representações Sociais, Psicanálise e Infância.

\section{CONSIDERAÇÕES}

Considerando sua época e o modelo de filosofia vigente, Espinosa contrariou a perspectiva predominante sobre as emoções/afetos. Partiu em defesa das emoções como parte da natureza humana, sem reduzir essa natureza às emoções, colocando-as como imanente ao ser humano, parte constituinte de seu processo de existência.

No geral, os artigos analisados mostram que Espinosa é tomado como um teórico da afetividade. Desconexa da definição proposta por sua teoria, os afetos aparecem como ilustração àquilo que é discutido, ou seja, apaga-se a própria reflexão do autor adequando-a conforme o campo ou epistemologia. Reitera-se aqui que Espinosa define sua filosofia à partir de uma concepção que considere as emoções como parte da formação humana, indissociável do universo racional. Percebe-se que na Psicologia estas tem sido trabalhadas num quadro geral e não especificas nos termos do autor, desprendidas do próprio sentido espinosano, da emoção e afecções como elemento nuclear para conhecer as ações humanas.

Nesses termos, a Psicologia entre seus vários usos daquilo que Espinosa formula em sua filosofia, ora afasta-se do proposto filosófico-reflexivo central nos determinantes da obra e ora aproxima-se categoricamente das afecções como elemento chave para o sujeito tornar-se ativo em sua existência frente os fenômenos estudados na atualidade.

Espinosa nos fala a todo momento sobre um sujeito que se constitui em meio à dinâmica do mundo e resgata suas experiências de afetação através de um corpo que é memorioso, formado pelas conexões de ideias e imagens de acordo com seu contexto de vida. Nos fala de um sujeito que se constitui no outro e com o outro, nos encontros, nas experiências e ideias do que é vivenciado. Assim, o sujeito espinosano é um movimento interno e externo de busca por perseverar em sua própria existência, se lançando para vida, para a ação.

A teoria de Espinosa nos impulsiona para dentro das ciências psicológicas, com base ontológica e epistemológica, conversa fluidamente com a história e a formação do ser humano. Em geral, o tema afetividade é fortemente discutido por toda comunidade psicológica, dos moldes do senso comum até atribuição fisiológica das emoções. Por fim, as Psicologias Sócio-Histórica e Histórico-Cultural, são epistemes que substancialmente buscam em Espinosa fundamentos para um sujeito que se humaniza ao mesmo momento em que está imerso no mundo com os outros, sendo afetado e afetando, evidenciando a urgência de historicização do fenômeno.

2 Sócio-histórica foi o conceito escolhido por Silvia Lane e sua equipe para nomear uma psicologia inspirada em Vigotski - histórico-cultural, atribuído à escola russa -, porém, considerando o pensamento marxista sobre a construção de uma sociedade que é permeada pela luta de classes, mas mantendo a ligação com a teoria de Vigotski ao ressaltar a dimensão material e histórica do fenômeno psicológico do sujeito (MAHEIRIE; SAWAIA, 2014, p. 2). 


\section{Referências}

BLOCH, Marc. Apologia da história ou o ofício de historiador. Rio de Janeiro: Jorge Zahar, 2001.

BRANDÃO, Israel Rocha. Afetividade e participação na metrópole: uma reflexão sobre dirigentes de ONGs da cidade de Fortaleza. 2008. Tese (Doutorado em Psicologia Social) - Pontifícia Universidade Católica de São Paulo, São Paulo. Disponível em: <https://sapientia.pucsp.br/bitstream/handle/17310/1/Israel\%20Rocha\%20Brandao.pdf >. Acesso em: 15 out. 2018 .

CHAUÍ, Marilena de Souza. Espinosa: vida e obra. In: Pensamentos metafísicos: Tratado da correção do intelecto: Ética: Tratado político: Correspondência. Tradução de Marilena de Souza Chauí et al. 3. ed. São Paulo: Abril Cultural, 1983. (Coleção Os Pensadores).

CHAUÍ, Marilena. Convite à Filosofia. São Paulo: Ática, 2000.

CHAUÍ, Marilena. Poder e liberdade: a política em Espinosa. Cadernos de Ética e Filosofia Política, São Paulo, n. 4, 2002.

COSTA, Áurea Júlia de Abreu; PASCUAL, Jesus Garcia. Análise sobre as emoções no livro Teoría de las emociones (Vigotski), Psicologia \& Sociedade, Belo Horizonte, v. 24, n. 3, p. 628-637, 2012 Disponível em: < http://www.scielo. br/scielo.php?pid=S0102-71822012000300016\&script=sci_abstract\&tlng=pt>. Acesso em: 21 ago. 2018.

EUZÉBIOS FILHO, Antônio; GUZZO, Raquel Souza Lobo. Marxismo e teoria da personalidade: uma análise do sujeito histórico, Cadernos Cemarx, n. 6, 2009. Disponível em: $<$ https://www.ifch.unicamp.br/ojs/index.php/cemarx/ article/viewFile/1088/785>. Acesso em: 15 out. 2018.

ESPINOSA, Baruch de. Pensamentos metafísicos: Tratado da correção do intelecto: Ética: Tratado político: Correspondência. Tradução de Marilena de Souza Chauí et al. 3. ed. São Paulo: Abril Cultural, 1983. (Os Pensadores).

MACHADO, Letícia Vier; FACCI, Marilda Gonçalves Dias; BARROCO, Sonia Mari Shima. Teoria das emoções em Vigotski, Psicol. Estud., Maringá, v. 16, n. 4, 2011. Disponível em: < http://www.redalyc.org/articulo. oa? $\mathrm{id}=287122492015>$. Acesso em: 21 ago. 2018.

MAGIOLINO, Lavínia Lopes Salomão; SMOLKA, Ana Luiza Bustamante. Afeto e emoção no diálogo de Vygotsky com Freud: apontamentos para a discussão contemporânea. 2010. Disponível em: < http://32reuniao.anped.org.br/ arquivos/trabalhos/GT20-5545--Int.pdf>. Acesso em: 21 ago. 2018.

MAHEIRIE, Katia; SAWAIA, Bader Burihan. A Psicologia sócio-histórica: um referencial de análise e superação da desigualdade social, Psicologia e Sociedade, v. 26, n. spe. 2, p.1-3, 2014. Disponível em: < http://www.scielo.br/scielo. php?script=sci_arttext\&pid=S0102-71822014000600001\&lang=pt $>$. Acesso em: 15 out. 2018.

PHILLIPIS, B. S. Pesquisa social: estratégias e táticas. Rio de Janeiro: Agir Editora, 1974.

PIMENTEL, Alessandra. O método da análise documental: seu uso numa pesquisa historiográfica, Cadernos de Pesquisa. n. 114, p. 179-195, 2001. Disponível em: < http://www.scielo.br/pdf/cp/n114/a08n114>. Acesso em: 27 out. 2018.

PROST, Antoine. Doze lições sobre a história. Belo Horizonte: Autêntica, 2008. 287p.

SAWAIA, Bader Burihan. A crítica ético-epistemológica da psicologia social pela questão do sujeito, Psicologia \& Sociedade, São Paulo, v. 10, n. 2, p. 117-136, 1998. Disponível em: < http://www4.pucsp.br/nexin/artigos/download/a-critica-etico-epistemologica.pdf>. Acesso em: 15 out. 2018.

SAWAIA, Bader Burihan. Psicologia e desigualdade social: uma reflexão sobre liberdade e transformação social, Psicologia \& Sociedade, São Paulo, v. 21, n. 3, p. 364-372, 2009. < http://www.scielo.br/pdf/psoc/v21n3/a10v21n3>. Acesso em: 15 out. 2018.

SAWAIA, Bader Burihan; SILVA, Daniele Nunes Henrique. Pelo reencantamento da Psicologia: em busca da positividade epistemológica da imaginação e da emoção no desenvolvimento humano, Cad. CEDES, v. 35, p. 343-360, 2015. Disponível em: < http://www.scielo.br/pdf/ccedes/v35nspe/1678-7110-ccedes-35-spe-00343.pdf>. Acesso em: 15 out. 2018.

VIGOTSKY, Lev Semyonovich. Teoría de las emociones: estudio histórico-psicológico. Madrid: Akal, 2004. 


\section{Documentos primários}

AZEVEDO, Lívia Godinho Nery Gomes et al. Experimentação política da amizade em comunidades da internet a partir da teoria dos afetos de Espinosa, Psicologia USP, São Paulo, v. 26, n. 2, p. 208-220, 2015. Disponível em: < http:// www.scielo.br/pdf/pusp/v26n2/0103-6564-pusp-26-02-00208.pdf>. Acesso em: 05 nov. 2018.

BRAZAO, José Carlos Chaves. A Implicação do Afeto na Psicologia do Desenvolvimento: uma Perspectiva Contemporânea, Psicologia: Ciência e Profissão, Brasília, v. 35, n. 2, p. 342-358, 2015. Disponível em: < http://www.scielo.br/ scielo.php?pid=S1414-98932015000200342\&script=sci_abstract\&tlng=pt $>$. Acesso em: 05 nov. 2018.

COSTA, Áurea Júlia de Abreu; PASCUAL, Jesus Garcia. Análise sobre as emoções no livro Teoría de las emociones (Vigotski), Psicologia \& Sociedade, Belo Horizonte, v. 24, n. 3, p. 628-637, 2012 Disponível em: < http://www.scielo. br/scielo.php?pid=S0102-71822012000300016\&script=sci_abstract\&tlng=pt>. Acesso em: 21 ago. 2018.

HINKEL, Jaison; MAHEIRIE, Kátia. Rap-rimas afetivas da periferia: reflexões na perspectiva sócio-histórica, Psicologia \& Sociedade, Porto Alegre, v. 19, n. spe 2, p. 90-99, 2007. Disponível em: <http://www.scielo.br/scielo.php?script=sci_arttext\&pid=S0102-71822007000500024\&lng=en\&nrm=iso>. Acesso em: 05 nov. 2018.

LOOS, Helga, SANT'ANA, René Simonato. Cognição, afeto e desenvolvimento humano: a emoção de viver e a razão de existir. Educar em Revista 2007. Disponível em: <http://www.redalyc.org/articulo.oa?id=155013356011>. Acesso em: 05 nov. 2018.

PEIXOTO JUNIOR, Carlos Augusto. Permanecendo no próprio ser: a potência de corpos e afetos em Espinosa, Fractal: Rev. Psicol., Rio de Janeiro, v. 21, n. 2, p. 371-385, 2009. Disponível em: < http://www.scielo.br/scielo.php?pi$\mathrm{d}=$ S1984-02922009000200012\&script=sci_abstract\&tlng=pt>. Acesso em: 21 ago. 2018.

PEIXOTO JUNIOR, Carlos Augusto; ARAN, Márcia. O lugar da experiência afetiva na gênese dos processos de subjetivação, Psicol. USP, São Paulo, v. 22, n. 4, p. 725-746, 2011. Disponível em: < http://www.redalyc.org/articulo. oa? id=305123742007>. Acesso em: 05 nov. 2018.

RIBEIRO, Marinalva Lopes; JUTRAS, France. Representações sociais de professores sobre afetividade, Estud. Psicol., Campinas, v. 23, n. 1, p. 39-45, 2006. Disponível em: < http://www.scielo.br/pdf/estpsi/v23n1/v23n1a05.pdf >. Acesso em: 05 nov. 2018.

SAWAIA, Bader Burihan. Teoria laneana: a univocidade radical aliada à dialética-materialista na criação da psicologia social histórico-humana, Psicol. \& Soc., Porto Alegre, v. 19, n. spe 2. p. 81-89, 2007. Disponível em: < http://www. scielo.br/scielo.php?pid=S0102-71822007000500023\&script=sci_abstract\&tlng=pt $>$. Acesso em: 05 nov. 2018.

SAWAIA, Bader Burihan. Psicologia e desigualdade social: uma reflexão sobre liberdade e transformação social, Psicol. \& Soc., Florianópolis, v. 21, n. 3, p. 364-372, 2009 Disponível em: < http://www4.pucsp.br/nexin/artigos/download/ psicologia-e-desigualdade-social.pdf $>$. Acesso em: 05 nov. 2018.

SAWAIA, Bader Burihan. Transformação social: um objeto pertinente à psicologia social? Psicol. \& Soc., Belo Horizonte, v. 26, n. spe2, p. 4-17, 2014. Disponível em: < http://www.scielo.br/pdf/psoc/v26nspe2/a02v26nspe2.pdf>. Acesso em: 05 nov. 2018.

SAWAIA, Bader Burihan; SILVA, Daniele Nunes Henrique. Pelo reencantamento da Psicologia: em busca da positividade epistemológica da imaginação e da emoção no desenvolvimento humano, Cad. CEDES, Campinas, v. 35, n. spe, p. 343-360, 2015. Disponível em: < http://www.scielo.br/pdf/ccedes/v35nspe/1678-7110-ccedes-35-spe-00343. pdf $>$. Acesso em: 05 nov. 2018.

SILVA, Daniele Nunes Henrique; MAGIOLINO, Lavínia Lopes Salomão. Dimensões (est)éticas e políticas da paixão entre Simone e Nelson, Psicol. \& Soc., Belo Horizonte, v. 28, n. 1, p. 45-54, 2016. Disponível em: <http://www.scielo. br/pdf/psoc/v28n1/1807-0310-psoc-28-01-00045.pdf.>. Acesso em: 05 nov. 2018.

SOUZA, Maria Thereza Costa Coelho de. As relações entre afetividade e inteligência no desenvolvimento psicológico, Psic.: Teor. e Pesq., Brasília , v. 27, n. 2, p. 249-254, 2011. Disponível em: < http://www.scielo.br/pdf/ptp/v27n2/ a05v27n2.pdf $>$. Acesso em: 05 nov. 2018. 
WORTMEYER, Daniela Schmitz; SILVA, Daniele Nunes Henrique; BRANCO, Angela Uchoa. Explorando o território dos afetos a partir de Lev Semenovich Vigotski, Psicol. Estud., Maringá , v. 19, n. 2, p. 285-296, 2014. Disponível em: $<$ http://www.scielo.br/pdf/pe/v19n2/11.pdf $>$. Acesso em: 05 nov. 2018.

VIANA CHAVES, Hamilton et al. Contribuições de Baruch Espinosa à teoria histórico-cultural, Psicol. em Revista., v. 18, n. 1, p. 134-147, abr. 2012 Disponível em: < http://pepsic.bvsalud.org/scielo.php?script=sci_arttext\&pi$\mathrm{d}=\mathrm{S} 1677-11682012000100011>$. Acesso em: 05 nov. 2018.

$\begin{array}{ll}\text { Histórico } & \text { Recebido em: 07/10/2019 } \\ & \text { Revisão em: } 13 / 05 / 2020 \\ & \text { Aceito em: 08/10/2020 } \\ & \text { Concepção: CAV; AGI } \\ & \text { Coleta de dados: CAV } \\ & \text { Análise de dados: CAV } \\ \text { Claboração do manuscrito: CAV; AGI } & \text { Revisões críticas de conteúdo intelectual importante: CAV; AGI } \\ & \text { Aprovação final do manuscrito: AGI; CAV } \\ & \\ & \text { Não houve financiamento } \\ & \end{array}$

